\title{
Acesso e qualidade da informação recebida sobre sexo e sexualidade na perspectiva adolescente
}

\section{Access and quality of information received on sex and sexuality from the adolescent perspective}

\section{Acceso y calidad de la información recibida sobre sexo y sexualidad en la perspectiva adolescente}

\section{Milene Fontana Furlanetto*}

Universidade do Vale do Rio dos Sinos - Unisinos, São Leopoldo, Rio Grande do Sul, Brasil

\section{Angela Helena Marin**}

Universidade Federal do Rio Grande do Sul - UFRGS, Porto Alegre, Rio Grande do Sul, Brasil

\section{Tonantzin Ribeiro Gonçalves***}

Universidade do Vale do Rio dos Sinos - Unisinos, São Leopoldo, Rio Grande do Sul, Brasil

\section{RESUMO}

O presente estudo, de delineamento explanatório sequencial, corte transversal e abordagem mista, buscou caracterizar o acesso e a qualidade da informação recebida sobre sexo e sexualidade nos contextos familiar e escolar a partir da perspectiva de adolescentes. Os participantes foram adolescentes do $6^{\circ}$ ao $9^{\circ}$ ano do ensino fundamental de duas escolas de São Leopoldo e quatro de Porto Alegre. Na etapa quantitativa, 253 jovens responderam ao Questionário de Dados Sociodemográficos e Comportamentos Sexuais, enquanto que na etapa qualitativa foram realizados grupos focais. Os dados foram analisados estatisticamente e por análise temática, destacando-se dois grandes temas: 1) fontes e limites de acesso às informações sobre sexo e sexualidade e 2) vieses da comunicação. A média de iniciação sexual foi de 13,7 anos $(D P=1,33)$ e 0 uso inconsistente de preservativo foi relatado por $40 \%$ dos participantes. Em conjunto, os dados sugerem uma lacuna entre a transmissão de informações sobre sexo e sexualidade nos contextos investigados e o comportamento preventivo dos adolescentes, revelando o escopo reduzido de temáticas abordadas, sentimentos de constrangimento e atitudes sexistas e homofóbicas. Destaca-se a necessidade de investimento em capacitação de profissionais para a realização da educação sexual na escola, visando atender não somente os adolescentes, mas também suas famílias.

Palavras-chave: educação sexual, adolescentes, habilidades na comunicação. 


\begin{abstract}
The present study, with a sequential explanatory delineation, cross - sectional and mixed approach, sought to characterize the access and quality of information received about sex and sexuality in family and school contexts from the perspective of adolescents. The participants were adolescents from the 6th to the 9th year of elementary school in two schools in São Leopoldo and four in Porto Alegre. In the quantitative stage, 253 young people answered the Questionnaire on Socio-demographic Data and Sexual Behaviors, while in the qualitative phase, focus groups were performed. The data were analyzed statistically and by thematic analysis, highlighting two main topics: 1) sources and limits of access to information about sex and sexuality and 2) communication bias. The average sexual initiation was 13.7 years $(S D=1.33)$, and inconsistent condom use was reported by $40 \%$ of participants. Together, the data suggest a gap between the transmission of information about sex and sexuality in the contexts investigated and the adolescents' preventive behavior, highlighting the reduced scope of the issues addressed, feeling of embarrassment and sexist and homophobic attitudes. It is important to emphasize the need for investment in training professionals to carry out sex education at school, in order to serve not only adolescents, but also their families.
\end{abstract}

Keywords: sex education, adolescents, communication skills.

\title{
RESUMEN
}

El presente estudio, de delineamiento explicativo secuencial, corte transversal y abordaje mixto, buscó caracterizar el acceso y la calidad de la información recibida sobre sexo y sexualidad en los contextos familiar y escolar desde la perspectiva de adolescentes. Los participantes fueron adolescentes del $6^{\circ}$ al $9^{\circ}$ año de la enseñanza fundamental de dos escuelas de São Leopoldo y cuatro de Porto Alegre. En la etapa cuantitativa, 253 jóvenes respondieron al Cuestionario de Datos Sociodemográficos y Comportamientos Sexuales, mientras que en la etapa cualitativa se realizaron grupos focales. Los datos fueron analizados estadísticamente y por análisis temático, destacándose dos grandes temas: 1) fuentes y límites de acceso a las informaciones sobre sexo y sexualidad y 2) sesgos de la comunicación. El promedio de iniciación sexual fue de 13,7 años ( $D P=1,33$ ), y el uso inconsistente de preservativo fue reportado por el $40 \%$ de los participantes. En conjunto los datos sugieren una laguna entre la transmisión de información sobre sexo y sexualidad en los contextos investigados y el comportamiento preventivo, revelándose el escaso de temáticas abordadas, sentimiento de constreñimiento y actitudes sexistas y homofóbicas. Se destaca la necesidad de inversión en capacitación de profesionales para la realización de la educación sexual en la escuela, buscando atender no sólo a los adolescentes, sino también a sus familias.

Palabras clave: educación sexual, adolescentes, habilidades en la comunicación.

A adolescência é uma etapa do ciclo vital caracterizada por mudanças biológicas e psicossociais, na qual geralmente ocorre o aumento da autonomia do adolescente de sua família, a aproximação ao grupo de pares e as primeiras experiências sexuais (Preto, 2011). As preocupações relativas à vivência sexual dos adolescentes consistem, principalmente, no risco de contaminação por doenças infecciosas e gestações não planejadas, tema que têm captado grande parte dos 
estudos produzidos (Oliveira, Béria, \& Schermann, 2014; Siegel, Lekas, Ramjohn, Schrimshaw, \& VanDevanter, 2014). No entanto, também existem riscos emocionais implicados nos relacionamentos, como a violência física e psicológica, que vão além das questões individuais do adolescente, já que estão atrelados a determinantes sociais, como, por exemplo, a forma como a cultura de determinado local promove ou significa dinâmicas desiguais de acesso e exercício dos direitos sexuais entre os gêneros (Cerqueira-Santos, Neto, \& Koller, 2014; Sevilla \& Orcasita, 2014). Assim, faz-se importante conhecer as particularidades dos contextos que participam da formação de conhecimento, valores e crenças em relação à sexualidade de adolescentes (Furlani, 2011).

A educação sexual pode ser compreendida como um processo permanente de ensino e aprendizagem sobre a sexualidade humana, seja de maneira formal ou informal (Figueiró, 2010). A educação formal desenvolve-se no âmbito do sistema educativo de maneira intencional, comprometida com uma didática sistemática, ancorada em pressupostos científicos e orientada para promover o conhecimento por parte de quem aprende. Já a educação sexual informal é um processo global, que ocorre de forma deliberada desde o nascimento, a partir das experiências do cotidiano, por meio da comunicação e transmissão de valores do contexto social e familiar, com repercussão direta ou indireta sobre a vida dos sujeitos (Figueiró, 2010).

A família é um dos principais contextos que influenciam na formação e desenvolvimento de opiniões e comportamentos relacionados à sexualidade. É no âmbito familiar que serão transmitidas, de distintas formas, as primeiras noções e valores associados à sexualidade, mesmo que não explicitamente (Preto, 2011). Contudo, estudos apontam importantes dificuldades para abordar a temática com os filhos/as, que incluem o sentimento de constrangimento, o desconhecimento sobre como e quando conversar sobre o assunto e barreiras advindas das próprias vivências sexuais dos pais, que podem ter sido mais repressoras em sua geração (Savegnago \& Arpini, 2016; Seloilwe, Magowe, Dithole, \& Lawrence, 2015; Sevilla \& Orcasita, 2014). Também é preciso destacar a influência de fatores sociais e culturais, que implicam em uma grande diversidade na forma de ensinar os filhos/as noções de sexualidade e em como lidar com a expressão da sexualidade na adolescência. Pessoas de classes socioeconômicas altas e de contextos urbanos tendem a ter maiores níveis de educação e avaliarem sua comunicação sobre sexualidade na família como mais qualificada do que nos contextos rurais e de baixo nível socioeconômico (Portugal \& Alberto, 2015; Preto, 2011).

Nesse sentido, a educação sexual escolar poderia oferecer aos alunos, desde a infância, espaços de aprendizagem comprometidos com uma cultura de prevenção e promoção da saúde sexual e também com atitudes coletivas de respeito às distintas formas de se relacionar, pautando-se pela ótica da garantia dos direitos humanos, 
particularmente dos direitos sexuais e reprodutivos (Furlani, 2011; Gava \& Villela, 2016). Todavia, no Brasil, há dificuldades para implementação da educação sexual, não somente por parte dos profissionais da escola, mas também por falta de ações programáticas de políticas públicas. Assim, frequentemente ela tem sido reduzida ao estudo da fisiologia humana e do aparelho reprodutivo (Furlanetto, Lauermann, Costa, \& Marin, 2018; Vieira \& Matsukura, 2017).

Segundo dados da Pesquisa Nacional de Saúde do Escolar (PeNSE) de $2016,87,3 \%$ dos escolares do 90 ano do ensino fundamental tem acesso a informações sobre sexualidade na escola, principalmente referentes às infecções sexualmente transmissíveis (IST), gravidez e características fisiológicas dos sexos (IBGE, 2016). Recentemente, 0 movimento "Escola sem Partido" tem defendido que as discussões sobre gênero e orientação sexual na escola fossem impedidas por entender que esta seria uma forma de doutrinação política e ideológica, o que pode representar um retrocesso na educação sexual escolar, visto que os casos de violência doméstica e sexual contra crianças e adolescentes estão associados à impossibilidade de discussão e pensamento crítico acerca das maneiras com que a cultura heteronormativa interfere nas relações de gênero entre homens e mulheres (Gava \& Villela, 2016; Colling, 2017).

Atualmente, discute-se que comportamentos sexuais associados a desfechos negativos, como aquisição de IST e gestações não planejadas, não estão relacionados apenas ao fato de ter ou não recebido informações sobre prevenção (Moura et al., 2013). Uma experiência mais saudável da sexualidade na adolescência também é influenciada por aspectos como preconceito e desigualdades nas relações de gênero, assim como aspectos contextuais, como nível socioeconômico, suporte familiar e a cultura na qual o sujeito está inserido (Moura et al., 2013; Spencer, Doull, \& Shoveller, 2012; Wang et al., 2013). Por fim, faz-se importante pontuar que a vivência da sexualidade na adolescência não se resume ao ato sexual propriamente dito. Ela integra os relacionamentos afetivos e as vivências sociais mais amplas, entre outros aspectos que serão relevantes para as experiências futuras. A forma como ocorre o desenvolvimento da aprendizagem sexual terá impacto nas vivências adultas posteriores, nas relações profissionais, no autocuidado em saúde e nas noções sobre cidadania (Louro, 2015). Assim, compreendendo a formação da identidade sexual como um processo amplo e contínuo, faz-se necessário avaliar o acesso e a qualidade da informação sobre sexo e sexualidade nos contextos familiar e escolar na perspectiva de adolescentes. 


\section{Método}

\section{Delineamento e participantes}

Trata-se de um estudo de delineamento explanatório sequencial (Creswel, 2007) de corte transversal e abordagem mista, que buscou caracterizar o acesso e a qualidade da informação recebida sobre sexo e sexualidade nos contextos familiar e escolar na perspectiva de adolescentes. Para etapa quantitativa, a amostra foi acessada por conveniência. Como critério de inclusão, os adolescentes deveriam estar cursando entre $\circ 6^{\circ}$ e $9^{\circ}$ ano do ensino fundamental e não poderiam ter idade superior aos 18 anos. Foram excluídos os adolescentes que apresentaram necessidades educativas especiais $(n=3)$. Assim, participaram 253 adolescentes, com idade média de 13,67 anos (DP = 1,$54 ; 61 \%$ meninas e $39 \%$ meninos). Eles estavam matriculados em duas escolas municipais de São Leopoldo $(n=127)$ e quatro escolas estaduais de Porto Alegre $(n=126)$, todas na região metropolitana do estado do Rio Grande do Sul. Em relação à classificação socioeconômica dos participantes, segundo o Critério Brasil, a maioria pertencia ao estrato médio, a saber: B2 $(31,1 \%)$, seguido do C1 $(27 \%)$, B1 $(21,7 \%), C 2(10,7 \%), A(7 \%)$ e $D(2,5 \%)$.

Para a etapa qualitativa, foi proposta de realização dos grupos focais com os adolescentes para todas as escolas participantes, mas apenas três aceitaram: duas da cidade de São Leopoldo (E1 e E2 - localizadas respectivamente nas regiões leste e centro) e uma de Porto Alegre (E3 localizada na região central). Na E1 participaram doze alunos do $9^{\circ}$ ano, sendo cinco meninos e sete meninas. Já na E2, foram quatro alunos do $7^{\circ}$ ano e o restante do $8^{\circ}$ ano, sendo um menino e sete meninas. Por fim, na E3 participaram oito alunos do $9^{\circ}$ ano, quatro meninos e quatro meninas. Foi pré-requisito para participação nos grupos que 0 adolescente tivesse participado da etapa quantitativa.

\section{Instrumentos e procedimentos de coleta de dados}

Inicialmente, todos os participantes responderam a um Questionário de dados Sociodemográficos e Comportamentos Sexuais, desenvolvido pelas autoras, para caracterizar o adolescente e sua família, assim como para investigar o conhecimento sobre sexualidade, comportamento sexual, informação e acesso a programas de educação sexual e comunicação sobre sexualidade no ambiente familiar e escolar. Este instrumento foi avaliado por meio de um estudo piloto com cerca de $10 \%$ do número total de participantes, que possibilitou revisar e aprimorar as questões. A aplicação foi feita pela primeira autora, que é psicóloga, além de uma bolsista de iniciação científica, graduanda do curso de psicologia e previamente treinada. A aplicação dos instrumentos durava, em média, 30 minutos. Após, formaram-se os 
grupos focais, também conduzidos pelas mesmas. Seguiu-se um roteiro semiestruturado que abordava aspectos referentes a comportamentos sexuais, educação sexual e diálogos sobre sexo e sexualidade. Todos os encontros foram gravados em áudio e vídeo e tiveram duração média de 50 minutos cada.

\section{Procedimentos éticos}

O presente estudo foi aprovado pelo Comitê de Ética em Pesquisa da Unisinos, sob CAEE no 66618717.9.0000.5344. Todos os princípios e cuidados éticos necessários à pesquisa com seres humanos foram atendidos, conforme a Resolução 510/16 do Conselho Nacional de Saúde.

Obteve-se anuência da Secretaria Municipal de Educação de São Leopoldo (SMED) e da Secretaria da Educação do Estado do Rio Grande do Sul (SEDUC). A partir do aceite das escolas convidadas, selecionadas por conveniência pela facilidade de acesso geográfico, o projeto foi apresentado às equipes pedagógicas, que sugeriram os melhores horários para acessar os alunos na escola. Eles participaram da pesquisa mediante ao Termo de Consentimento Livre e Esclarecido assinado por um responsável, os quais eram enviados e devolvidos por eles próprios. Os adolescentes também assinaram um Termo de Assentimento, no qual constava os objetivos de pesquisa e explicações referentes ao sigilo e direito de desistência, permitindo a compreensão pelos mesmos da natureza do estudo.

\section{Procedimentos de análise de dados}

Os dados do questionário foram analisados quantitativamente, considerando suas distribuições absoluta e relativa, bem como as medidas de tendência central e dispersão. Já o material produzido nos grupos focais foi examinado por meio da análise temática indutiva, considerando a linguagem verbal e não verbal dos participantes. Os temas foram definidos a partir dos assuntos abordados, considerando os objetivos do estudo (Braun \& Clarke, 2006).

Para familiarização com o material foi feita uma primeira leitura flutuante e, após, os relatos foram reunidos em grandes temas, observados de modo recorrente em todas as entrevistas. O software NVivo foi utilizado para organização dos temas, que foram definidos a partir dos assuntos abordados e considerando os objetivos do estudo: 1) fontes e limites de acesso às informações sobre sexo e sexualidade, com as subcategorias: a) família; b) amigos e mídia, e c) escola; e 2) vieses da comunicação, com a subcategoria: a) sexismo e homofobia. 


\section{Resultados e Discussão}

Dentre os 253 adolescentes, 80 já haviam tido iniciação sexual (55\% meninas e $45 \%$ meninos) quando tinham, em média, 13,6 anos $(\mathrm{DP}=1,33)$, sendo que $40 \%$ deles (17 meninas e 15 meninos) relatou não ter usado preservativo na primeira ou última relação sexual que haviam tido. A idade de iniciação sexual anterior aos 15 anos é considerada precoce e tem sido identificada tanto na literatura nacional quanto internacional como associada a maiores chances do não uso do preservativo, o que pode implicar o contágio por IST ou gestações não planejadas (Oliveira et al., 2014; Siegel et al., 2014). Nesse sentido, uma das estratégias de enfrentamento do HIV/Aids tem sido proporcionar informações a respeito da forma de contágio, a fim de que as pessoas possam conhecer os riscos implicados nas relações sexuais e analisar se há necessidade de mudança em suas práticas sexuais (Moura et al., 2013). A Tabela 1 descreve as fontes de acesso, a qualidade da informação recebida pelos adolescentes e a percepção quanto ao seu nível de conhecimento. 


\begin{tabular}{|c|c|c|}
\hline $\begin{array}{l}\text { Como considera seu nível de conhecimento sobre sexo e } \\
\text { sexualidade? }\end{array}$ & $\mathrm{n}$ & $\%$ \\
\hline Muito baixo/Baixo & 46 & 18,2 \\
\hline Médio & 102 & 40,3 \\
\hline Bom/Excelente & 105 & 41,5 \\
\hline \multicolumn{3}{|l|}{ Como obteve as primeiras informações? } \\
\hline Familia & 108 & 42,7 \\
\hline Amigos & 79 & 31,2 \\
\hline Internet & 70 & 27,7 \\
\hline Escola & 51 & 20,2 \\
\hline \multicolumn{3}{|c|}{ Com quem se sente confortável para conversar ou tirar dúvidas? } \\
\hline Familia & 125 & 49,4 \\
\hline Amigo & 115 & 45,5 \\
\hline Internet & 55 & 21,7 \\
\hline Profissionais escola & 11 & 4,3 \\
\hline \multicolumn{3}{|l|}{ Informações sobre sexo e sexualidade na Família } \\
\hline \multicolumn{3}{|l|}{ Avaliação da qualidade informação } \\
\hline Ruim/Fraco & 120 & 47,4 \\
\hline Médio & 32 & 12,6 \\
\hline Bom/Excelente & 101 & 39,9 \\
\hline \multicolumn{3}{|l|}{ Gostaria de falar mais? } \\
\hline Sim & 96 & 37,9 \\
\hline Não & 157 & 62,1 \\
\hline \multicolumn{3}{|l|}{$\begin{array}{l}\text { Informações sobre sexo e sexualidade na Escola } \\
\text { Avaliação da qualidade informação }\end{array}$} \\
\hline Ruim/Fraco & 115 & 45,5 \\
\hline Médio & 61 & 24,1 \\
\hline Bom/Excelente & 77 & 30,4 \\
\hline \multicolumn{3}{|l|}{ Gostaria de falar mais? } \\
\hline Sim & 189 & 75,6 \\
\hline Não & 61 & 24,1 \\
\hline
\end{tabular}

Como pode ser identificado acima, grande parte dos adolescentes acreditavam ter um nível de conhecimento bom à excelente sobre sexo e sexualidade. A Pesquisa de Conhecimentos, Atitudes e Práticas na População Brasileira (PCAP), de 2013, do Ministério da Saúde, entrevistou 3.142 jovens de 15 a 24 anos, encontrando um percentual médio de respostas corretas sobre as formas de transmissão e prevenção do HIV de 73,1\%. Mesmo assim, apenas 19,9\% relataram uso de preservativo em todas relações sexuais com parceiros fixos e 58,8\% com parceiros casuais (Brasil, 2013). A mesma discrepância entre o conhecimento e práticas sexuais foi encontrada em outros estudos, o que sugere a necessidade de investigar outros fatores que influenciam o comportamento e possam ser incluídos na educação sexual (Moura et al,, 2013; Oliveira, Béria, \& Schermann, 2014). Os achados dos grupos focais possibilitaram entender, de modo mais aprofundado, as percepções de risco, o acesso e a qualidade das informações sobre sexualidade entre os adolescentes. As análises 
derivaram dois grandes temas de discussão, os quais são apresentados e discutidos a seguir, integrando os dados quantitativos aos qualitativos.

\section{Fontes e limites de acesso às informações sobre sexo e sexualidade}

O aprendizado sobre o uso de preservativo e outras formas de cuidados com a saúde sexual ocorre nos principais ambientes com os quais o sujeito interage durante sua vida. Entretanto, falar sobre sexualidade costuma trazer constrangimento, o que, em parte, remete a construção histórica da sexualidade como um conteúdo de forte conotação moral, que teve períodos de maior repressão, limitando tais discussões às esferas médicas e psiquiátricas (Louro, 2015). A partir das revoluções sociais da metade do século $X X$, como o movimento feminista e 0 LGBTQI+ (Lésbicas, Gays, Bissexuais, Travestis, Transexuais, Transgêneros, Queer, Intersexuais e outros), os direitos sexuais e reprodutivos foram reivindicados e houve o desenvolvimento de políticas públicas direcionadas aos ideais de liberdade e autonomia de decisão, vinculando a sexualidade à promoção de saúde e qualidade de vida. Nesse sentido, é importante citar a Conferência Internacional sobre População e Desenvolvimento do Cairo, em 1994, que enfatizou a necessidade da criação de programas de informação e orientação sexual para adolescentes, considerando-os sujeitos de direito (Moraes \& Vitalle, 2015). Nessa direção, no Brasil, os Parâmetros Curriculares Nacionais (PCN) de 1998, avançaram ao propor que o tema da sexualidade fosse trabalhado em todas as disciplinas, de forma transversal (Furlanetto et al., 2018; Moraes \& Vitalle, 2015).

Mesmo com esses incentivos para o trabalho nas escolas, os adolescentes deste estudo indicaram a família como o primeiro contexto no qual receberam informações sobre o tema e que se sentiam mais confortáveis para conversar ou tirar dúvidas sobre sexo e sexualidade ${ }^{1}$, seguido dos amigos, internet e profissionais da escola. Apesar disso, as informações recebidas da família foram avaliadas pela maioria como ruins ou fracas, já que não os auxiliavam com suas principais dúvidas. Ainda, $62,1 \%$ declararam que não gostariam de falar sobre o assunto com algum familiar, o que aponta para dificuldades em estabelecer esse diálogo.

Coadunando com esses achados, os relatos nos grupos focais, evidenciaram que, em sua maioria, as conversas na família costumavam ser limitadas a informações pontuais, por vezes com tom de ameaça, principalmente relativas ao cuidado com gestações não planejadas e aquisição de IST: "meu pai diz: 'usa camisinha guri'!" $(\mathrm{E} 1 \mathrm{~A} 11){ }^{2}$; "se aparecer com filho aqui, ó!" (E1A10). Hyde et al. (2013) já tinham atentado que a comunicação sobre sexualidade nas famílias 
costuma apresentar muitas falhas, ocorrendo de maneira direta, mas superficial, ou indireta, por meio insinuações e intimidação, não deixando claro o que se quer comunicar. Um adolescente relatou a tentativa de o pai conversar sobre o assunto, ilustrando essas dificuldades: "Eu tava no quarto e meu pai chegou e queria saber o que eu entendia sobre sexo. Na hora eu fiquei com a cara toda vermelha e disse que não queria falar sobre aquilo naquele momento. Ele disse que então depois a gente conversava. Depois ele voltou e falou mais sobre eu me prevenir, cuidar e doenças" (E3A3).

Dentre os temas mais conversados nas famílias, destacaram-se a prevenção de IST e gestações não planejadas, o que corrobora dados de outros estudos como o de Savegnago e Arpini (2016). O foco na prevenção pode ser devido a ser menos constrangedor para os pais e também para os filhos, quando comparado a outros temas, como prazer e orientação sexual, por exemplo: "É que a pessoa não se sente muito confortável falando desse assunto com os pais" (E1A7); "Parece que os pais têm vergonha de falar também" (E1A10). Assim, mesmo que os pais saibam da importância da educação sexual em ambiente familiar e façam tentativas de comunicação com os filhos, eles encontram dificuldades de efetivá-la (Savegnago \& Arpini, 2016; Seloilwe et al., 2015).

Sobre as percepções dos adolescentes acerca desses diálogos, mesmo que tenham apontado a família como um ambiente confortável, foi possível identificar que a maioria não queria ampliar as conversas sobre a temática em casa: "Minha mãe é mais aberta comigo, mas eu não consigo ser com ela. Não me sinto confortável" (E1A4); "Eu não falo em casa porque tenho vergonha e não gosto de falar" (E1A2). Esta última adolescente mencionou a intergeracionalidade como uma barreira comunicacional: "Eu acho que a minha mãe não fala porque ela disse que a minha avó nunca foi muito de conversar. Daí eu acho que ela nunca conversou comigo porque a educação dela foi assim" (E1A2). Sobre isso, entende-se que a transmissão de padrões de interação entre os membros da família é de grande importância para o desenvolvimento individual e relacional dos sujeitos (Bowen, 1978). Principalmente em relação à sexualidade, a cada nova geração inseremse novas configurações e dinâmicas nos relacionamentos, sendo necessário que a geração anterior se adapte as mudanças para acolher e orientar os mais jovens (Preto, 2011; Sevilla \& Orcasita, 2014).

As barreiras assinaladas no diálogo com os familiares podem levar os adolescentes a procurarem outras fontes de informação. Assim, os amigos tiveram resultados muito próximos ao da família no levantamento quantitativo, sendo o segundo meio mais frequente pelo qual os adolescentes relataram ter tido as primeiras informações sobre sexualidade e com quem se sentiam mais confortáveis para dialogar. Para alguns, a procura de amigos parecia trazer alívio, sendo esta uma fonte considerada confiável e válida de informação, como ilustram os 
relatos dos grupos focais: "A gente fala com os amigos que sabem" (E1A10); "É que às vezes tem vontade de falar alguma coisa para os pais, mas sentem medo, aí falam com os amigos" (E2A9). Entende-se que a interação com os amigos representa um amplo espaço no cotidiano dos adolescentes, permitindo a socialização e a experimentação de relações afetivas e habilidades sociais. Muitas vezes os amigos se tornam a principal fonte de intimidade na adolescência, servindo como modelo e influenciando comportamentos e atitudes. Assim, o envolvimento do adolescente com um grupo de amigos com atitudes de risco pode aumentar a chance desse adolescente também assumir comportamentos arriscados, no entanto, esse desfecho vai estar associado também com a comunicação e supervisão da família (Tomé, Matos, Simões, Camacho, \& Diniz, 2013).

Também é próprio da adolescência e da atualidade o uso das tecnologias de informação e comunicação. Elas foram citadas tanto na busca por informação, quanto no diálogo com amigos pelo uso do celular: "A gente fala com os amigos no whatsapp" (E1A10); "Em qualquer lugar (da internet) tu tem como saber daquilo que tu quer" (E1A9); "Na internet tu tem duas opções, ou tu vê como é (se referindo a vídeos), ou tu pesquisa" (E1A4). A internet foi relatada como fonte de informações sobre sexo e sexualidade por $27,7 \%$ dos participantes, assim como um ambiente confortável para tirar dúvidas $(21,7 \%)$. Considerando o crescimento do uso dos dispositivos móveis de acesso à internet nos últimos anos (Comitê Gestor da Internet no Brasil [CGI.BR], 2017), essa frequência pode ser considerada baixa o que talvez se relacione a um menor nível socioeconômico dos participantes, que compunham em torno de $40,2 \%$ da amostra, ou a sua baixa média de idade.

O acesso à internet sem supervisão dos responsáveis pode permitir que o adolescente acesse conteúdos com informações distorcidas sobre sexo e sexualidade (Seloilwe et al., 2015). Isto, aliado a falta de diálogo familiar e educação sexual escolar pode favorecer a exposição a riscos sexuais e emocionais. Por exemplo, foram observadas situações de exposição íntima de alunos pelas mídias sociais, sendo que, em uma delas, culminou na saída de uma adolescente da escola, conforme relatado em um dos grupos: "Teve o caso também de uma menina ano passado, que mandou uma foto para um menino e ele foi lá e espalhou. Toda escola sabia da foto dela, ela teve que sair da escola" (E1A4).

Como exposto neste estudo, ainda se percebe a família e a escola como referência para os adolescentes, em detrimento às mídias sociais. Nesse sentido, mais uma vez, atenta-se para a necessidade de a educação sexual nesses contextos agregar qualidade aos processos comunicativos e de aprendizagem sobre a temática. A escola foi indicada por $75,6 \%$ dos participantes como o local no qual gostariam de falar mais sobre 0 tema, mesmo que não se sentissem tão confortáveis para isso e apesar de as informações nela obtidas tenham sido avaliadas, em sua maioria, 
como ruins ou fracas. Segundo os participantes dos grupos focais, essas informações eram obtidas principalmente na disciplina de Ciências, enfocando temas como anatomia do corpo, reprodução e métodos contraceptivos e preventivos. Também houve divergência sobre a eficácia da abordagem utilizada. Por um lado, os adolescentes manifestaram descontentamento referente ao escopo reduzido dos temas apresentados, bem como sobre a didática objetiva e meramente expositiva dos conteúdos, que não facilitava o diálogo entre professores e alunos: "Eles falam (professores), mas não o necessário, caso tu não tivesse outra fonte de informação, sabe?" (E2A5); "Acho que não deveria ser uma coisa muito mecânica: só o professor fala e os alunos ouvem. Acho que deveria ser uma troca" (E1A4). Por outro lado, alguns acreditavam que as aulas ajudavam a perceber o risco de contaminação por doenças e apresentaram informações relevantes: "Ajuda um pouco, porque tu vê ali a doença e não gostaria de pegar" (E3A8).

Estudos têm identificado que a educação sexual nas escolas brasileiras costuma ser limitada ao modelo biológico-centrado e preventivo, sendo que não contempla aspectos como os diferentes modos de vivenciar a sexualidade (Furlanetto et al., 2018; Gava \& Vilella, 2016). Enquanto as transformações sociais e políticas inserem novas discussões como, por exemplo, novas tecnologias reprodutivas, diversidade de articulações entre sexo biológico, gênero e práticas sexuais, relações virtuais, entre tantos outros temas, a escola segue apresentando aos alunos os mesmos conteúdos sobre sexualidade desde o início do século XX (Louro, 2015). Embora se reconheça que essas informações são importantes, destaca-se a necessidade de abranger outras temáticas que incitem novas reflexões e dialoguem com os contextos sociais e interesses dos adolescentes.

O sentimento de confiança dos participantes mostrou-se relevante para que se pudesse estabelecer um diálogo franco com os profissionais da escola. O receio da exposição íntima e a possibilidade de conflito com os familiares foram os principais motivos pelos quais os adolescentes não participavam de discussões ou não perguntavam suas dúvidas nas aulas: "A gente quer tirar uma dúvida, elas (professoras) criam um problema e quando vão falar pros nossos pais, aumentam o problema" (E3A2); "Eu não tenho confiança pra falar sobre isso na escola" (E1A5). Esse pode ser parte do motivo pelo qual poucos adolescentes $(4,3 \%)$ apontaram a escola como espaço confortável para falar sobre a temática no levantamento quantitativo. Corroborando com estes achados, o trabalho de Sevilla e Orcasita (2014) identificou que entre as principais barreiras para os estudantes acessarem a escola como apoio para suas experiências sexuais estavam o medo de que as informações chegassem aos pais, as habilidades limitadas de negociação dos profissionais com o adolescente e a percepção dos espaços como hostis. Por outro lado, um número expressivo de adolescentes apoiou que a educação sexual ocorresse na escola. Mesmo que ainda não se sintam 
confortáveis ou confiantes nela, se mostravam mais receptivos por essa aproximação com o tema na escola do que com as famílias. Inclusive, indicaram que se houvesse um profissional confiável na escola, este seria escolhido para esclarecer suas dúvidas sobre sexo e sexualidade, em detrimento a outras pessoas da família ou rede social: "Eu acho que se a gente falasse mais sobre isso na escola seria melhor" (E3A1); "Eu preferiria conversar na escola, mas dependendo da pessoa" (E1A4).

Os adolescentes ainda destacaram que gostariam de obter as informações sobre sexo e sexualidade na escola por meio de uma metodologia mais participativa e menos expositiva. Por exemplo, eles sugeriram roda de conversa ou discussões que possibilitassem espaços de diálogo entre os alunos e professores, apontando o momento da realização do grupo focal como ilustrativo do tipo de conversa que gostariam de ter: "Queria que fosse algo mais aberto, assim como está sendo agora" (E2A4). Uma menina expressou a necessidade de se sentir respeitada pela equipe escolar: "Eu queria respeito. Além deles aconselharem a gente sobre proteção, eu queria que respeitassem mais a escolha sexual" (E3A2). Em relação aos temas que gostariam de ter mais informações destacaram-se: idade para a primeira relação sexual, uso de medicações anticoncepcionais e seus efeitos, estupro, aborto, além dos temas relativos à anatomia e prevenção de doenças que, em geral, já seriam trabalhados, especialmente nas escolas.

Os adolescentes costumam ter grande curiosidade sobre sexo e sexualidade, e quando o ambiente proporciona conforto e confiança é possível que eles relatem mais suas experiências e dúvidas, como visto em alguns estudos de intervenção que realizaram oficinas com adolescentes escolares (Ew, Conz, Faria, Sombrio, \& Rocha, 2017; Freitas \& Dias, 2010). Essa forma de trabalho implica que o facilitador da oficina consiga acolher o que o participante traz em uma postura de respeito a sua opinião, que pode ser confrontada com as diferentes percepções e vivências dos outros participantes, fazendo emergir novas reflexões (Ew et al., 2017; Freitas \& Dias, 2010; Furlani, 2011). Assim, é importante a capacitação do profissional para que atitudes e concepções discriminatórias sobre a sexualidade possam ser identificadas e trabalhadas nos grupos. Como se verá na próxima categoria, acredita-se que tais atitudes afetam diretamente a qualidade das informações recebidas.

\section{Vieses da comunicação: sexismo e homofobia}

Em diversas falas nos grupos focais foi possível perceber que as orientações que eram dadas pelos pais sobre sexualidade eram baseadas no gênero dos filhos, sugerindo uma maior repressão do comportamento sexual das meninas: "Minha mãe não me deixou ir numa festa porque ela disse que só ia ter guri e que se ela deixasse eu 
ir iam me chamar de puta" (E1A2); "Quando eu tive um namorado teve pressão por parte do avô, agora se fosse meu primo, por exemplo meu vô ia tá, tipo....wow (torcendo)" (E2A4). Ainda, observou-se evidências de concepções discriminatórias dos pais em relação a orientações sexuais distintas do padrão heteronormativo: "Eu não me importo com o fato da minha mãe ser machista, só que o problema é que ela fica me oprimindo e eu digo pra ela que tá sendo homofóbica, mas ela não aceita" (E3A2). Sevilla e Orcasita (2014) ressaltam que a visão dos direitos sexuais e reprodutivos a partir de uma perspectiva de gênero acaba por não ser percebida pela maioria dos pais, que transmitem valores conservadores e rígidos em relação aos papéis sexuais, mesmo que não intencionalmente.

$\mathrm{Na}$ escola, os adolescentes também identificavam atitudes preconceituosas dos professores sobre gênero e sexualidade: "A professora $X$ diz que as meninas não podem jogar futebol. Ela falou isso" (E3A2); "A monitora falou que se ela tivesse um filho ou uma filha gay ela iria espancar, porque ela não aceitaria isso" (E3A5). Estudos pontuam que existem lacunas em termos de formação de professores para lidar com as questões de gênero, sexualidade e diversidade na escola, o que faz com que usem suas experiências pessoais como modelo (Furlanetto et al., 2018; Madureira \& Branco, 2015). Eles também temem que ao abordar esse assunto com os alunos possam sofrer represália dos pais ou da direção, o que faz com que prefiram se abster de buscar mais informações e aprimorar sua didática (Madureira \& Branco, 2015). O mesmo é visto na situação dos pais, que percebem mudanças em relação a educação sexual que tiveram em sua época de adolescentes e a de hoje em dia com seus filhos. Muitos receberam informações limitadas e padrões conservadores quanto aos papéis sexuais e de gênero, o que parece dificultar o diálogo com seus filhos na atualidade (Sevilla \& Orcasita, 2015).

Os estereótipos de gênero vividos na família e na escola parecem interferir na forma como meninas e meninos dialogam sobre sexualidade (Louro, 2015). Especialmente entre as meninas, identificou-se um excessivo cuidado com o que e com quem se falava sobre seu comportamento: "É que os guris falam mais livremente pra todo mundo que quiser ouvir, sabe? As gurias são mais fechadas, falam só entre elas" (E2A5). Para os meninos, também parece existir uma norma do que se espera deles, uma conduta viril e se relacionar com muitas meninas: "Meu pai diz: 'pode comer geral, só não vai engravidar"' (E1A12); "Às vezes tu tá num grupinho e todo mundo fala. Tu mente muitas vezes, né? Digamos, assim, tem gente que fala: Ah! Peguei 19! Tu não quer ficar isolado, tipo: "eu nunca fiz" (E1A7).

O sentimento de que existiria uma única norma a ser seguida também afeta o diálogo sobre orientação sexual como evidenciado no único caso, dentre os grupos, de uma menina que se declarou bissexual e referiu ter cuidado ao conversar com as pessoas sobre o tema, pois 
sentia que podia sofrer algum preconceito: "Quando eu sei se ele é homofóbico ou não, se ele acha estranho ou não. Eu não falo se ele achar estranho, e se ele não achar eu falo, mas bem discretamente!" (E3A2). No caso dos adolescentes não heterossexuais, as dificuldades encontradas nos ambientes discriminatórios podem interferir ainda mais na comunicação, acarretando tanto riscos sexuais quanto emocionais, como depressão e ideação suicida (Teixeira-Filho \& Rondini, 2012).

De modo geral, evidenciou-se que os participantes dos grupos focais, na maioria das vezes, não conseguiam fazer uma reflexão crítica sobre os fundamentos sociais e culturais dos estereótipos de gênero vividos no seu cotidiano. Desta forma, grande parte relatava situações de risco sexual, físico e emocional, como sendo de responsabilidade individual, sendo que às meninas era delegado ter mais reponsabilidade em relação ao uso de preservativo: "Quem geralmente lembra de usar é a menina né, porque o menino não quer" (E1A8). Além disso, as meninas também tendiam a ser responsabilizadas pela exposição pública e comentários depreciativos que recebiam, enquanto os meninos, por não se envolverem sentimentalmente nas relações: "Tem guria que gosta de ser mal falada e tem guri que espalha pra todo mundo (que teve relação sexual). Eles são assim porque eles querem" (E1A5). Apesar disso, alguns participantes apontaram e questionaram a influência da cultura no julgamento sobre um mesmo tipo de comportamento entre meninos e meninas: "Tem preconceito, né? Porque se o guri fala assim: peguei essa, essa e essa, ele é pegador, se a guria fala isso ela é puta" (E1A7).

Salienta-se que as estratégias de educação sexual não devem atentar apenas aos comportamentos de risco, como tem sido observado na maioria dos estudos (Spencer et al., 2012), mas para a reflexão de que os diálogos também carregam normas sociais e culturais conservadoras sobre sexo e sexualidade que podem ser adotadas pelos adolescentes sem questionamento, tornando-os mais vulneráveis (Louro, 2015). Nesse sentido, defender que a escola não pode se manifestar politicamente sobre as situações de discriminação de gênero é se posicionar a favor da manutenção deste sistema que gera exclusões, violência e mais riscos à saúde. A escola é o ambiente propício para esse debate, já que tem compromisso com a formação moral e cidadã de seus alunos (Figueiró, 2010; Furlani, 2011). O mesmo ocorre nas famílias, que têm demonstrado dificuldade para transcender à educação sexual que receberam, em sua maioria repressiva e heteronormativa (Portugal \& Alberto, 2015; Sevilla \& Orcasita, 2014). Assim, é necessário promover e integrar ações do sistema público de educação e saúde, capacitando profissionais para realizarem uma educação sexual baseada nos direitos sexuais e reprodutivos dos alunos, incluindo suas famílias. 


\section{Considerações finais}

Os comportamentos sexuais na adolescência têm sido uma preocupação entre profissionais e pesquisadores, pois podem se relacionar com importantes problemas de saúde pública. Os esforços têm se concentrado prioritariamente na transmissão de informações preventivas e em menor proporção na qualidade e formas de veiculálas. É preciso atentar também para o fato de que a sexualidade é componente da identidade dos sujeitos, relacionando-se com aspectos individuais, emocionais, sociais, culturais e históricos. A iniciação sexual na adolescência tem sido permeada por um discurso que enfatiza os riscos individuais ligados à relação sexual propriamente dita, como o uso inconsistente de preservativo. Porém, aspectos sociais e relacionais como o sexismo e a homofobia podem implicar em sofrimento subjetivo e isolamento e, portanto, em maior vulnerabilidade. A comunicação sobre sexualidade recebida tanto da família quanto da escola foi predominantemente avaliada como precária pelos adolescentes, especialmente devido ao constrangimento daqueles que se propõem a dialogar sobre o tema, que se restringe as esferas reprodutivas e preventivas. Entre pais e filhos, tal sentimento parece se acentuar, embora o ambiente propicie maior conforto que a escola, local em que os adolescentes julgavam que se poderia aprender mais sobre sexo e sexualidade. Contudo, como esta prática ainda não acontece efetivamente, os amigos e a internet parecem suprir, ao menos em parte, a carência de informações. A internet é um meio em que os adolescentes têm livre acesso aos mais diversos temas que, muitas vezes, podem não ter a melhor qualidade, especialmente quando se acredita que já se sabe bastante sobre o assunto, como é o caso dos participantes do presente estudo. Tal constatação pode apontar para a presença de uma baixa percepção de risco entre os adolescentes.

Faz-se, portanto, necessário que o interesse dos adolescentes pelas questões relativas a sexo e sexualidade sejam contempladas de forma a atender suas demandas, buscando-se potencializar a escola com novas estratégias de ensino-aprendizagem que promovam uma cultura de promoção em saúde e trabalhem o tema como um construto histórico, social, cultural, além de biológico. Essa parceria entre escola e serviço de saúde é contemplada no Brasil a partir do Programa Saúde na Escola (PSE), do Ministério da Saúde (Russo \& Arreguy, 2015). No entanto a promoção de saúde requer metodologias de trabalho participativas, que superem a visão de doença vinculada as experiências sexuais dos adolescentes. Para isso seria necessário não somente palestras informativas e disponibilização de preservativos, mas também a participação ativa dos adolescentes a partir da discussão de suas próprias percepções sobre a sua sexualidade e os principais focos de interesse e dúvidas (Freitas \& Dias, 2010; Souza, Esperidião, \& Medina, 2017). Dessa forma, acredita-se que os adolescentes poderão, 
inclusive, reconhecer normas e valores heteronormativos, hegemônicos na sociedade, posicionando-se criticamente em relação ao conservadorismo que ainda perpassa famílias, escolas e meios de comunicação.

Por fim, é importante reconhecer algumas limitações do estudo. 0 tempo disponibilizado pelas escolas para realização do grupo focal, que ficaram, em média, restritos a um período de aula, aproximadamente 50 minutos, pode ter limitado a investigação de questões adicionais. Além disso, o grupo que foi formado por adolescentes de turmas diferentes apresentou mais dificuldades para interagir livremente, enquanto os outros grupos que foram formados por alunos da mesma turma, que tinham mais intimidade, e talvez por isso, conseguiram expor mais suas vivências. Ainda, se recomenda que futuros estudos investigem as especificidades dos processos comunicativos de acordo com os diversos contextos socioeconômicos e características familiares, como configuração e estrutura, já que são escassos os estudos com esse escopo. Os achados representam adolescentes ainda na etapa inicial da fase e pertencentes a classes sociais mais baixas. Desse modo, outros estudos podem avançar avaliando diferenças entre adolescentes de diferentes classes sociais e em momentos distintos do desenvolvimento. Por fim, sugere-se incluir a percepção dos familiares e dos profissionais da escola a respeito de seus processos comunicativos sobre esta temática.

\section{Referências}

Bowen, M. (1978). La terapia familiar en la practica clinica: Fundamentos teóricos. Bilbao, Spain: Desclee de Brouwer.

Brasil. Ministério da Saúde, Secretaria de Vigilância em Saúde. Departamento de DST, Aids e Hepatites Virais. (2013). Pesquisa de conhecimento, atitudes e práticas na população brasileira. Recuperado de http://www.aids.gov.br/pt-br/pub/2016/pesquisade-conhecimentos-atitudes-e-praticas-na-populacao-brasileirapcap-2013

Braun, V., \& Clarke, V. (2006). Using thematic analysis in psychology. Qualitative Research in Psychology, 3(2), 77-101. doi:10.1191/1478088706qp063oa

Cerqueira-Santos, E., Neto, O. C. M., Koller, S. (2014). Adolescentes e adolescências. In L. F. Habigzang, E. Diniz, \& S. H. Koller (Orgs.), Trabalhando com adolescentes: teoria e intervenção psicológica (pp. 17-30). Porto Alegre: Artmed.

Colling, A. M. (2017). O que representa a proposta de ideologia de gênero e escola sem partido? In M. N. Strey, \& N. A. P. Souza (Orgs.), Corpo e relações de gênero na contemporaneidade (pp. 135). Porto Alegre: Edipucrs. 
Comitê Gestor da Internet no Brasil - CGI.BR. (2017). Pesquisa sobre o uso das tecnologias de informação e comunicação nas escolas brasileiras: TIC educação 2016. São Paulo: Núcleo de Informação e Coordenação do Ponto BR. Retrieved from: http://cetic.br/publicacao/pesquisa-sobre-o-uso-das-tecnologiasde-informacao-e-comunicacao-nas-escolas-brasileiras-ticeducacao-2016/

Creswel, J. W. (2007). Projeto de pesquisa: Método qualitativo, quantitativo e misto (2a ed.). Porto Alegre: Artmed.

Ew, R. A. S., Conz, J., Farias, A. D. G. O., Sombrio, P. B. M., \& Rocha, K. B. (2017). Diálogos sobre sexualidade na escola: Uma intervenção possível. Psicologia em Pesquisa, 11(2), 51-60. doi: $10.24879 / 2017001100200155$

Figueiró, M. N. D. (2010). Educação sexual: Retomando uma proposta, um desafio. Londrina: Eduel.

Freitas, K. R., \& Dias, S. M. Z. (2010). Percepções de adolescentes sobre a sua sexualidade. Texto e Contexto de Enfermagem, 19(2), 351357. doi:10.1590/S0104-07072010000200017

Furlanetto, M. F., Lauermann, F., Costa, C. B., \& Marin, A. H. (2018). Educação sexual em escolas brasileiras: Revisão sistemática da literatura. Cadernos de Pesquisa, 48(168), 550-71. doi: $10.1590 / 198053145084$

Furlani, J. (2011). Educação sexual na sala de aula: Relações de gênero, orientação sexual e igualdade étnico-racial numa proposta de respeito às diferenças. Belo Horizonte: Autêntica.

Gava, T., \& Villela, W. V. (2016). Educação em sexualidade: Desafios políticos e práticos para a escola. Sexualidad, Salud y Sociedad, 24, 157-171. doi:10.1590/1984-6487.sess.2016.24.07.a

Hyde, A., Drennan, J., Butler, M., Howlett, E., Carney, M., \& Lohan, M. (2013). Parent's constructions of communication whit their children about safer sex. Journal of Clinical Nursing, 22(23-24), 3438-3446. doi:10.1111/jocn.12367

Instituto Brasileiro de Geografia e Estatística - IBGE. (2016). Pesquisa Nacional da Saúde do Escolar: 2015. Rio de Janeiro: IBGE. Recuperado de https://biblioteca.ibge.gov.br/visualizacao/livros/liv97870.pdf

Louro, G. L. (2015). O corpo educado: Pedagogias da sexualidade. Belo horizonte: Autêntica.

Madureira, A. F. A., \& Branco, A. U. (2015). Gênero, sexualidade e diversidade na escola a partir da perspectiva de professores. Temas em Psicologia, 23(3), 577-591. doi:10.9788/TP2015.3-05

Moraes, S. P., \& Vitalle, M. S. S. (2015). Direitos sexuais e reprodutivos na adolescência: Interações ONU-Brasil. Ciência \& Saúde Coletiva, 20(8), 2523-2531. doi:10.1590/1413-81232015208.03112014

Moura, L. R., Lamounier, J. R., Guimarães, P. R., Duarte, J. M., Beling, M. T. C., Pinto, J. A., Goulart, E. M. A., \& Grillo, C. F. C. (2013). A 
lacuna entre o conhecimento sobre o HIV/AIDS e o comportamento sexual: Uma investigação com adolescentes de Vespasiano, Minas Gerais, Brasil. Caderno de Saúde Pública, 29(5), 1008-1018. doi:10.1590/S0102-311X2013000500018

Oliveira, N. P., Béria, J. U., \& Schermann, L. B. (2014). Sexualidade na adolescência: Um estudo com escolares da cidade de Manaus/AM. Aletheia, 43(44), 129-146. Recuperado de http://pepsic.bvsalud.org/scielo.php?script=sci_arttext\&pid=S1413 $-03942014000100010$

Portugal, A. P. M., \& Alberto, I. M. M. (2015). Caracterização da comunicação entre progenitores e filhos adolescentes: Estudo das variáveis sóciodemográficas. Ciência e Saúde coletiva, 20(5), 1389-1400. doi:10.1590/1413-81232015205.13222014

Preto, N. G. (2011). Transformação do sistema familiar na adolescência. In B. Carter, \& M. McGoldrick (Orgs.), As mudanças no ciclo de vida familiar: uma estrutura para a terapia familiar (pp. 223-230). Porto Alegre, RS: Artmed.

Russo, K., \& Arreguy, M. E. (2015). Projeto "Saúde e prevenção nas escolas": percepções de professores e alunos sobre a distribuição de preservativos masculinos no ambiente escolar. Physis: Revista de Saúde Coletiva, 25(2), 501-523. doi:10.1590/S010373312015000200010

Savegnago, S. D. O., \& Arpini, D. M. (2016). A abordagem do tema sexualidade no contexto familiar: $O$ ponto de vista de mães adolescentes. Psicologia: Ciência e Profissão, 36(1), 130-144. doi:10.1590/1982-3703001252014

Seloilwe, E. S., Magowe, M. M., Dithole, K., \& Lawrence, J. S. (2015). Parent and youth communication patterns on HIV and AIDS, STIs and sexual matters: opportunities and challenges. Journal of Child and Adolescence Behavior, 3(203), 1-6. doi:10.4172/23754494.1000203

Sevilla, T. M., \& Orcasita, L. T. (2014). "Hablando de sexualidade": Una mirada de los padres y las madres a los procesos de formación con sus hijos/as adolescentes en estratos populares de Cali. Avances en Enfermería, 32(2), 191-205. doi: 10.15446/av.enferm.v32n2.46097

Siegel, K., Lekas, H. M., Ramjohn, D., Schrimshaw, E. W., \& VanDevanter, N. (2014). Early life circumstances as contributors to HIV infection. Social Work Health Care, 53(9), 969-993. doi:10.1080/00981389.2014.931321

Sousa, M. C., Esperidião, M. A., \& Medina, M. G. (2017). A intersetorialidade no Programa Saúde da Escola: Avaliação do processo político gerencial e das práticas de trabalho. Ciência e Saúde Coletiva, 22(6), 1781-1790. doi:10.1590/141381232017226.24262016 
Spencer, G., Doull, M., \& Shoveller, J. A. (2012). Examining the concept of choice in sexual health interventions for young people. Youth \& Society, 46(6), 756-778. doi:10.1177/0044118X12451277

Teixeira-Filho, F. S., \& Rondini, C. A. (2012). Ideações e tentativas de suicídio em adolescentes com práticas sexuais hetero e homoeróticas. Saúde Sociedade São Paulo, 21(3), 651-667. doi:10.1590/S0104-12902012000300011

Tomé, G., Matos, M. G., Simões, C., Camacho, I., \& Diniz, J. A. (2013). How can peer group influence the behavior of adolescentes: Explanatory model. Global Journal of Health Science, 4(2), 26-35. doi: $10.5539 /$ gjhs.v4n2p26

Vieira, P. M., \& Matsukura, T. S. (2017). Modelos de educação sexual na escola: Concepções e práticas de professores do ensino fundamental da rede pública. Revista Brasileira de Educação, 22(69), 453-474. doi:10.1590/s1413-24782017226923

Wang, B., Stanton, B., Li, X., Cottrell, L., Deveaux, \& Kaljee, L. (2013). The influence of parental monitoring and parente-adolescent communication on Bahamian adolescente risk involvement: A three-year longitudinal examination. Social Science \& Medicine, 97, 161-169. doi:10.1016/j.socscimed.2013.08.013

\section{Endereço para correspondência Milene Fontana Furlanetto \\ Rua Felipe de Oliveira, 1000, Petrópolis, CEP 90630-000, Porto Alegre - RS, Brasil Endereço eletrônico: mileneff@gmail.com}

\section{Angela Helena Marin}

Rua Ramiro Barcelos, 2600 sala 221, Santa Cecília, CEP 90035-003, Porto Alegre - RS, Brasil

Endereço eletrônico: marin.angelah@gmail.com

\section{Tonantzin Ribeiro Gonçalves}

Escola de Saúde

Avenida Unisinos, 950, CEP 93022-750, São Leopoldo - RS, Brasil

Endereço eletrônico: tonanrib@yahoo.com.br

Recebido em: 23/09/2018

Reformulado em: 13/09/2019

Aceito em: 02/10/2019

\section{Notas}

* Mestre em Psicologia Clínica.

** Doutora em Psicologia.

*** Doutora em Psicologia.

${ }^{1}$ Os adolescentes poderiam indicar mais de uma opção nas questões "como/com quem obteve as primeiras informações sobre sexo e sexualidade" e "com quem se sente à vontade para conversar ou tirar dúvidas sobre sexo e sexualidade".

2 As letras e os números indicam a escola onde o grupo focal foi realizado e o adolescente que proferiu a fala. 
Milene Fontana Furlanetto, Angela Helena Marin, Tonantzin Ribeiro Gonçalves

Este artigo de revista Estudos e Pesquisas em Psicologia é licenciado sob uma Licença Creative Commons Atribuição-Não Comercial 3.0 Não Adaptada. 